\title{
Drug Product: Manufacturer(s)
}

National Cancer Institute

\section{Source}

National Cancer Institute. Drug Product: Manufacturer(s). NCI Thesaurus. Code C79342.

An entity that produces drug products and eng ages in current Good Manufacturing

Practice (cGMP) activities as regulated and enforced by the US Food and Drug

Administration (FDA). 